\title{
Relation between Free Volume and the Low-Temperature "Beta" Transition in Glassy Polycarbonate
}

\author{
Michael Gary WyzgoskI \\ Department of Materials and Metallurgical Engineering, \\ The University of Michigan, Ann Arbor, \\ Michigan, U.S.A. \\ Gregory Soh-Yu YEH \\ The Macromolecular Research Center, \\ The University of Michigan, \\ Ann Arbor, Michigan, U. S. A.
}

(Received March 8, 1972)

\begin{abstract}
The addition of plasticizer or antiplasticizer to polycarbonate has been reported to cause specific volume decreases. Also antiplasticizer has been reported to suppress the "beta" transition in polycarbonate. In order to study the relation between free volume and the beta molecular motion as well as the effect of these variables on mechanical properties we have examined polycarbonate films containing various amounts of plasticizer (dibutyl phthalate) or antiplasticizer (Arochlor 5442). Specific volume, dynamic mechanical, and tensile measurements were obtained. Results showed that 10-\% dibutyl phthalate and 30-\% Arochlor 5442 suppress almost completely the lowtemperature "beta" transition with a corresponding fractional volume loss of 0.015 at $25^{\circ} \mathrm{C}$ for both mixtures. Tensile measurements indicate $10-\%$ dibutyl phthalate increases tesile yield strength whereas 30-\% Arochlor 5442 increases both modulus and yield strength. Results are discussed in terms of current free volume concepts.
\end{abstract}

KEY WORDS Free Volume / Beta Transition / Polycarbonate /

The high impact strength of glassy polycarbonate has been suggested to relate to a high free volume and the existence of a large lowtemperature "beta" transition below the "alpha" or glass transition ${ }^{1,2}$. This communication presents data showing the relation between the magnitude of the fractional volume change and the intensity of the beta molecular motion in polycarbonate. Previous studies by Robeson and Faucher $^{3}$ had indicated that addition of $30 \%$ of an antiplasticizer (Arochlor 5460) to polycarbonate caused a suppression of the lowtemperature beta transition. Although density changes were not reported for this mixture, in another report Jackson and Caldwell ${ }^{4}$ had noted density increases of $2-2.5 \%$ over the expected values for films containing antiplasticizer (Arochlor compounds) or plasticizer (dibutyl phthalate). The amount of additive in these films was not reported. The data presented in this study defines how both specific volume and the low-temperature beta transition in polycarbonate change as a function of concentration for both an antiplasticizer (Arochlor 5442, a chlorinated terphenyl) and a plasticizer (dibutyl phthalate). Dibutyl phthalate was selected for this study based upon a previous report of its plasticizing effect on polycarbonate ${ }^{5}$.

\section{EXPERIMENTAL}

Polycarbonate samples containing various amounts of the low-molecular-weight additives were prepared by casting films 1-2-mils thick from solutions in methylene chloride. A bisphenol A polycarbonate (from a commercial source) of weight-average molecular weight 35000 with no additives was used. Solvent was removed by evaporation at room temperature $24 \mathrm{hr}$ followed by heating in a vacuum oven at 
a temperature $5-10^{\circ} \mathrm{C}$ above the glass-transition temperature of the mixture for about one hour. Infrared examination of the films containing plasticizer showed no change in intensity of absorption bands attributed to the plasticizer before and after heating; whereas, an absorption band due to the solvent was eliminated. For the less volatile antiplasticizer weight loss experiments indicated negligible losses occurred even for the pure additive at the temperatures employed for solvent removal. The films were amorphous as shown by wide-angle X-ray patterns and examination of surface replicas in an electron microscope. Density, and thus specific volume, was measured at $25^{\circ} \mathrm{C}$ with a density gradient column and in some cases a flotation technique. The dynamic mechanical properties were measured on a Rheovibron dynamic viscoelastometer under oscillating tensile stress at a frequency of $110 \mathrm{~Hz}$.

\section{RESULTS}

The effect on the beta transition of adding dibutyl phthalate and Arochlor 5442 is shown by changes in the loss factor, $\tan \delta$, and stored modulus, $E^{\prime}$, as a function of temperature in
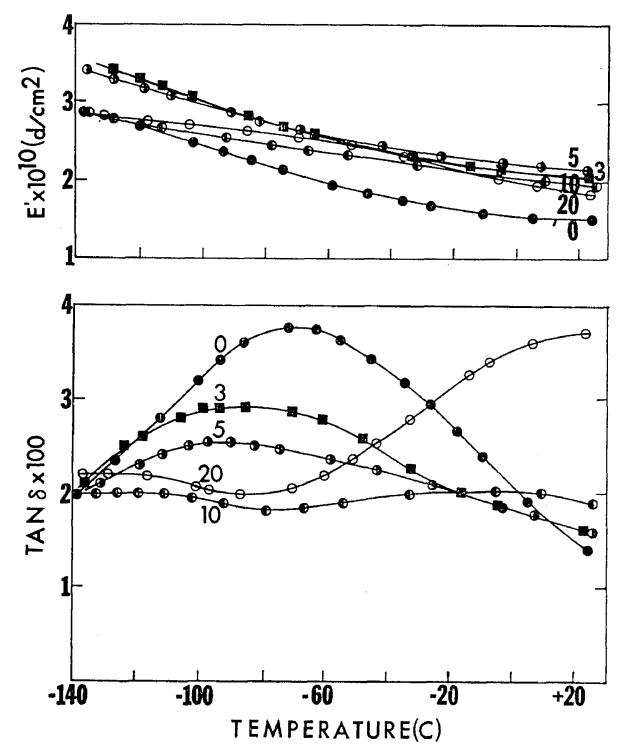

Figure 1. Polycarbonate with dibutyl phthalate. Numbers indicate weight percent of dibutyl phthalate in blend.
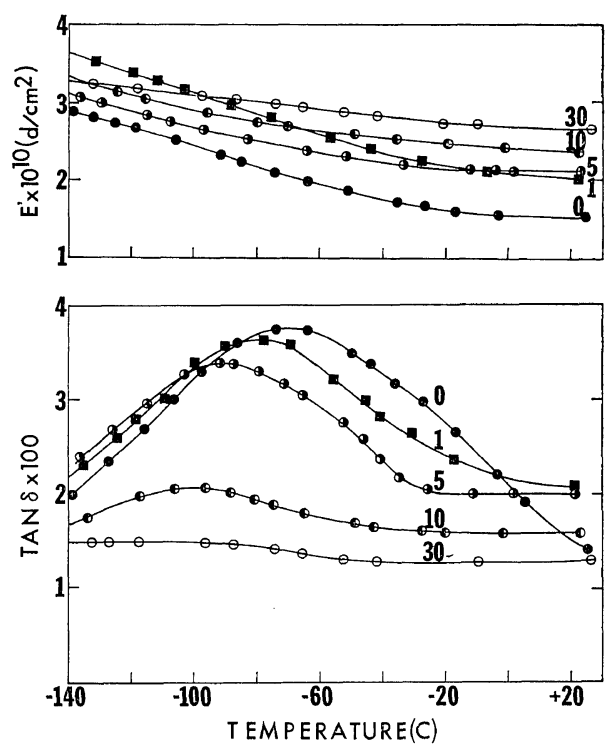

Figure 2. Polycarbonate with Arochlor 5442. Numbers indicate weight percent of Arochlor 5442 in blend.

Figures 1 and 2 . In both cases the intensity of the beta peak as shown by the area under the $\tan \delta$ curve decreases and the peak in $\tan \delta$ shifts to lower temperatures. The data shows that the high temperature side of the beta peak is depressed by increasing amounts of additive until the entire peak is eliminated. This occurs for samples containing more than 10-\% dibutyl phthalate and more than 30-\% Arochlor 5442. For $20-\%$ dibutyl phthalate a large transition is observed at higher temperatures. This is believed to be the onset of the "alpha" or glass transition which occurs at about $45^{\circ} \mathrm{C}$ for this mixture ${ }^{5}$. The changes in the polycarbonate beta peak upon addition of either Arochlor 5442 or dibutyl phthalate are similar to the effect of dioctyl phthalate on the beta peak for poly(vinyl chloride) as reported by Pezzin ${ }^{6}$. Robeson and Faucher $^{3}$ also showed that addition of $n$-phenyl2-napthylamine suppressed the beta peak of polysulfone while Arochlor 5460 suppressed the beta peak in polycarbonate. In addition, Robeson ${ }^{7}$ reported the suppression of the beta peaks for the systems polysulfone-Arochlor 5442, poly(vinyl chloride)-Arochlor 5460, and Bisphenol A poly(hydroxyether)-Arochlor 5460. 


\section{Relation between Free Volume and Beta Transition}

A slight shift of the peak in $\tan \delta$ to lower temperatures was also observed for these mixtures. For these polymers it appears that the addition of low-molecular-weight liquids gives similar results on the beta peaks.

The changes in stored modulus, $E^{\prime}$, also show similar results for both dibutyl phthalate and Arochlor 5442. For all concentrations of additives reported here, the stored moduli are higher than for pure polycarbonate at $110 \mathrm{~Hz}$. The stored modulus increases above the beta transition temperature as the concentration of Arochlor 5442 is increased. This agrees with the finding of Robeson and Faucher that elimination of the beta transition contributes to the increased modulus of antiplasticized polycarbonate above the beta transition temperature. The dibutyl phthalate also causes the stored modulus above the beta transition to increase but the magnitude of the increase is less than that observed for the Arochlor 5442. For the 20-\% dibutyl phthalate the stored modulus is seen to be decreasing above the beta transition temperature, probably due to the onset of the glass transition.

The changes in specific volume as a function of additive concentration can be expressed in terms of the expected specific volume $\left(V_{\text {exp }}\right)$, the experimentally measured specific volume $\left(V_{\text {meas }}\right)$, and the polymer apparent specific volume $\left(V_{\mathrm{app}}\right)$. The expected specific volume is the sum of the corresponding volumes of the separated polymer and additive. This is compared to the specific volume of the mixture which is experimentally measured to calculate the apparent specific volume of the polymer as: $\quad V_{\text {app }}=V_{\mathrm{p}}-\left(V_{\mathrm{exp}}-V_{\text {meas }}\right) / W_{\mathrm{p}} ; \quad$ where $V_{\mathrm{p}}(=0.837)$ is the specific volume of pure polycarbonate at $25^{\circ} \mathrm{C}$ and $W_{\mathrm{p}}$ is the weight fraction of polymer. This assumes that the observed changes in specific volume of the mixtures are due to changes in the specific volume of the polymer. The fractional volume loss as a result of adding the low-molecular weight liquids is calculated as: $\Delta V / V=\left(V_{\mathrm{p}}-V_{\mathrm{app}}\right) / V_{\mathrm{p}}$. Values of $V_{\text {exp }}, V_{\text {meas }}, V_{\text {app }}$, and $\Delta V / V$ are shown in Table I. Figure 3 shows plots of $V_{\text {app }}$ and $\Delta V / V$ as a function of concentration of additive.

The data in Table I clearly shows the
Table I. Specific volume of polycarbonate plus additives

\begin{tabular}{lrllll}
\hline Additive & \multicolumn{3}{c}{ Weight, } \\
& $\%$ & & & & \\
& & & & & \\
& & & & \\
Dibutyl phthalate & 3 & 0.840 & 0.838 & 0.835 & 0.002 \\
& 5 & 0.843 & 0.837 & 0.831 & 0.007 \\
& 10 & 0.850 & 0.837 & 0.824 & 0.015 \\
& 20 & 0.860 & 0.838 & 0.809 & 0.033 \\
Arochlor 5442 & 5 & 0.829 & 0.828 & 0.836 & 0.001 \\
& 10 & 0.821 & 0.819 & 0.835 & 0.002 \\
& 15 & 0.813 & 0.808 & 0.831 & 0.007 \\
& 30 & 0.790 & 0.781 & 0.824 & 0.015 \\
& 40 & 0.774 & 0.764 & 0.820 & 0.020 \\
& 50 & 0.758 & 0.748 & 0.817 & 0.024 \\
& 60 & 0.743 & 0.733 & 0.812 & 0.030
\end{tabular}

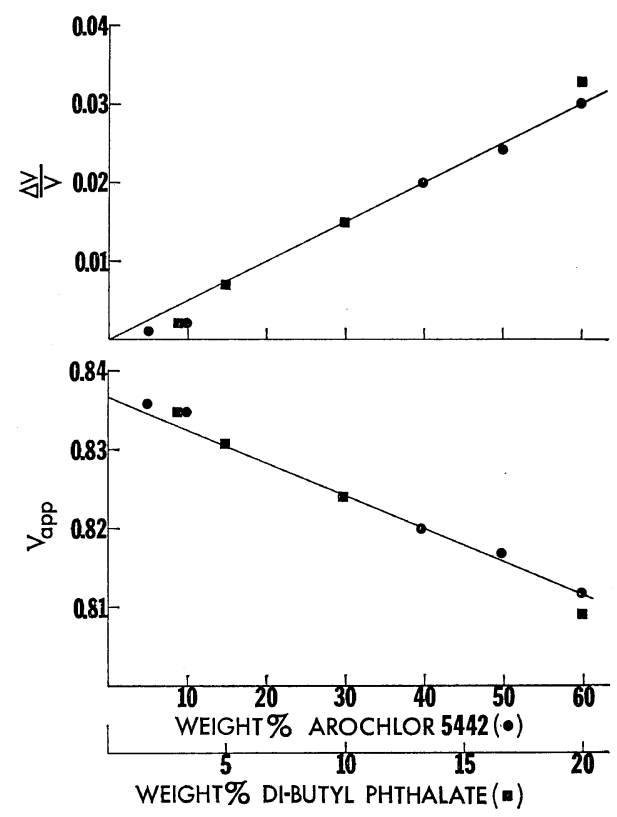

Figure 3. Polycarbonate fractional volume loss $(\Delta V / V)$, (top), and apparent specific volume $\left(V_{\mathrm{app}}\right)$, (bottom), vs. additive concentration.

measured specific volume of polycarbonate blends is less than the expected volume. The magnitude of the volume loss is directly proportional to the amount of additive. Also there is a direct relation between the volume loss and the intensity of the beta $\tan \delta$ peak. The elimination of the beta peak corresponds 
Table II. Tensile properties of polycarbonate blends

\begin{tabular}{lcccc}
\hline Material & $\begin{array}{c}\text { Modulus, } \\
\times 10^{5} \text { psi }\end{array}$ & $\begin{array}{c}\text { Yield } \\
\text { strength, } \\
\times 10^{3} \text { psi }\end{array}$ & \multicolumn{2}{c}{ Elongation, $\%$} \\
\hline $\begin{array}{l}\text { Polycarbonate } \\
\text { Polycarbonate with }\end{array}$ & 2.9 & 8.7 & 5.3 & 15 \\
$\begin{array}{l}10-\% \text { dibutyl } \\
\text { phthalate }\end{array}$ & 3.2 & 7.6 & 3.6 & 4.8 \\
$\begin{array}{l}\text { Polycarbonate with } \\
\text { 30-\% Arochlor }\end{array}$ & 4.2 & 11.2 & 3.0 & 3.0 \\
\hline 5442
\end{tabular}

to a fractional volume loss of 0.015 . This occurs for blends with more than 10-\% dibutyl phthalate or more than 30-\% Arochlor 5442.

The tensile properties of polycarbonate with 10-\% dibuthyl phthalate and 30-\% Arochlor 5442 are given in Table II. The blend with $10-\%$ dibutyl phthalate exhibits a ductile failure with a yield stress lower than pure polycarbonate while the blend with 30-\% Arochlor 5442 exhibits a brittle failure with a yield stress higher than pure polycarbonate. Both blends show increased moduli and decreased elongation to yield. The results for Arochlor 5442 agree with previous reports of the "antiplasticizing" effect of Arochlor compounds mixed with polycarbonate $^{4}$. The results for dibutyl phthalate indicate true "plasticization" is not occurring for polycarbonate with 10-\% dibutyl phthalate. Equating toughness to the area under the stress strain curve suggests that $10-\%$ dibutyl phthalate does embrittle polycarbonate. The embrittling effect is however much less than that observed for the antiplasticizer, Arochlor 5442, and the different effect on tensile properties should be emphasized in view of the similar effects these two additives have on the beta transition and fractional volume loss.

\section{DISCUSSION}

The data presented here agree with the density increase reported by Jackson and Caldwell ${ }^{4}$ for polycarbonate mixed with dibutyl phthalate or Arochlor 5442. Volume decreases corresponding to the suppression of a low-temperature transition have been reported for other polymers. For poly(vinyl chloride) ${ }^{6}$ the addition of $12-\%$ dioctyl phthalate caused a decrease in intensity of the beta transition and a corresponding volume loss of 0.01 (based on our method of calculation). The beta peak is eliminated in polysulfone by addition of Arochlor 5442, Arochlor 5460 or $n$-phenyl-2-naphthylamine and in Bisphenol A poly(hydroxyether) by addition of Arochlor $5460^{3,7}$. For these blends volume losses were noted only for low concentrations of additive. The blends with higher concentrations $[>10 \%]$ of additive which result in elimination of the beta loss peak in these polymers show volume increases. This does not agree with the data presented here for polycarbonate blends which shows a continuous volume decrease as a function of additive concentration. Volume losses have also been reported for polystyrene ${ }^{1,8}$ and poly(methyl methacrylate $)^{8}$, upon addition of low-molecular-weight liquids. For these cases no concurrent studies of low-temperature transition changes were reported.

\section{FREE VOLUME}

It is interesting to compare the experimentally observed volume losses with the polymer "free" volume calculated from theory. For this discussion we follow the definition given by Ferry $^{9}$ (and others ${ }^{10}$ ) for the WLF free volume. In general the specific volume of the glass (or the liquid) is given as the sum of an occupied volume $\left(V_{0}\right)$ and a free volume $\left(V_{\mathrm{f}}\right)$, or: $V=$ $V_{0}+V_{\mathrm{f}}$. The fractional free volume, $f=V_{\mathrm{f}} / V$, is obtained experimentally by application of the WLF equation. At $T_{\mathrm{g}}$, the glass transition temperature, a value of $f_{\mathrm{g}}$ of 0.025 is generally found for amorphous polymers. Above $T_{\mathrm{g}}$ the rate of change of $f$ with temperature is given by $f=f_{\mathrm{g}}+\alpha_{\mathrm{f}}\left(T-T_{\mathrm{f}}\right)$ where $\alpha_{\mathrm{f}}=\alpha_{1}-\alpha_{0} ; \alpha_{1}$, coefficient of expansion of liquid; $\alpha_{0}$, coefficient of expansion of occupied volume. Below $T_{\mathrm{g}}$ in the glassy state the rate of decrease of $f$ is given by $f=f_{\mathrm{g}}-\alpha_{\mathrm{f}}^{\prime}\left(T_{\mathrm{g}}-T\right)$ where $\alpha_{\mathrm{f}}^{\prime}=\alpha_{\mathrm{g}}-\alpha_{\mathrm{g}} ; \alpha_{\mathrm{g}}$, coefficient of expansion of the glass. For polycarbonate one can find reported values of $f_{\mathrm{g}}$ of $0.025^{11}$ and $0.029^{12}$. Values of $\alpha_{\mathrm{g}}=2.0 \times$ $10^{-4} /{ }^{\circ} \mathrm{C}^{13}$ and $\alpha_{\mathrm{g}}=2.8 \times 10^{-4} /{ }^{\circ} \mathrm{C}^{11}$ (from $100^{\circ} \mathrm{C}$ to $T_{\mathrm{g}}$ ) have been reported and $\alpha_{\mathrm{g}}$ is not expected to be constant from $25^{\circ} \mathrm{C}$ to $T_{\mathrm{g}}{ }^{14}$. The occupied 
volume expansion coefficient $\alpha_{0}$ can be set equal to $\alpha_{1}-\alpha_{\mathrm{f}}=1.1 \times 10^{-4} /{ }^{\circ} \mathrm{C}^{11}$ or set equal to $\alpha_{\text {crystal }}=1.26 \times 10^{-4} /{ }^{\circ} \mathrm{C}^{15}$. From these coefficients a range of values of fractional "free" volume from a minimum of $f=0.010$ to a maximum of $f=0.020$ can be calculated at $25^{\circ} \mathrm{C}$ for polycarbonate.

Having defined a measure of fractional free volume it is possible to consider the effect of adding a low-molecular-weight liquid on this "free" volume. Numerous authors have applied free volume theory to polymer-liquid systems to explain the observed decrease in the glass transition temperature of the mixture ${ }^{16,17}$. The significant feature of this theory to the present discussion is that the WLF fractional free volume $(f)$ of the polymer is decreased as the concentration of liquid increases. Obviously if the polymer free volume frozen into the glass at the glass transition of the mixture decreases, then the polymer free volume at any lower temperature also decreases. According to Kovacs $^{16}$ the point at which the WLF free volume reaches zero is indicated in a plot of the glass transition temperature of the mixture vs. concentration of liquid as an inflection or change in slope.

In summary, from the above discussion one would expect the WLF free volume, $f$, of the polymer to decrease by the addition of liquids. The value of $f$ for polycarbonate is calculated to be 0.01 to 0.02 at $25^{\circ} \mathrm{C}$ and that the elimination of this WLF free volume by the addition of liquid should be observed as an inflection in a plot of $T_{\mathrm{g}} v s$. concentration of liquid.

\section{COMPARISON WITH EXPERIMENTAL RESULTS}

Table I shows the fractional volume loss $(\Delta V / V)$ measured for polycarbonate at $25^{\circ} \mathrm{C}$ as a result of adding Arochlor 5442 or dibutyl phthalate. The fractional volume loss $(\Delta V / V)$ measured for polycarbonate at $25^{\circ} \mathrm{C}$ to suppress the beta transition is 0.015 . The fact that similar volume losses and changes in the beta transition occur for either Arochlor 5442 or dibutyl phthalate suggests that the observed volume loss upon suppression of the beta transition is independent of additive.

If we assume the observed volume losses are actually "free" volume losses for the polymer, then the similar magnitude of the observed volume loss $(\Delta V / V=0.015)$ to suppress the beta transition in comparison with the calculated value ( $f=0.01$ to 0.020 ) suggest that adding enough liquid to eliminate the WLF free volume results in a suppression of the beta transition. In other words we could conclude that the beta molecular motion is related to the WLF free volume. However, one cannot arbitrarily equate the observed volume loss to a "free" volume loss for the polymer since a change in the "free" volume of the additive is equally possible. Furthermore, changes in occupied volume are also possible for either the polymer or additive or both. In fact the measured fractional volume losses (see Table I) for more than 40\% Arochlor 5442 (or 13\% dibutyl phthalate) are greater than the maximum calculated fractional "free" volume at $25^{\circ} \mathrm{C}$ $(f=0.020)$. This indicates that for these higher concentrations we must also assume that changes in occupied volume are occurring. Although the assignment of volume loss to either "free" or occupied volume or both is somewhat arbitrary, an independent experiment can be performed to provide further evidence for associating the beta molecular motion with the WLF free volume.

From differential scanning calorimeter measurements of the decrease of $T_{\mathrm{g}}$ for polycarbonate mixed with Arochlor $5442 \mathrm{we}^{18}$ have observed an inflection or change in slope at a concentration of 30 to $40 \%$. According to Kovacs this is the concentration of Arochlor 5442 required to eliminate the WLF free volume of the polymer, and as shown in Figure 2 it corresponds to the concentration which eliminates the beta transition.

In summary both the comparison of observed fractional volume losses $(\Delta V / V)$ with the calculated WLF "free" volume $(f)$ at $25^{\circ} \mathrm{C}$ and the inflection observed in the decrease of $T_{\mathrm{g}}$ with concentration of additive seem to indicate that the beta molecular motion is associated with the WLF free volume. It can be argued that the correlations cited here are 
"coincidental." Further data is required on other polymer-liquid blends to show the validity of these correlations.

\section{REFERENCES}

1. M. H. Litt and A. V. Tobolsky, J. Macromol. Sci. (Phys.), B1(3), 433 (1967).

2. R. F. Boyer, Polym. Eng. Sci., 8, No. 3, 161 (1968).

3. L. M. Robeson and J.A. Foucher, Polymer Letters, 7, 35 (1969).

4. W. J. Jackson, Jr., and J. R. Caldwell, Advan. Chem. Ser., 48, 185 (1965).

5. P. V. Kozlov, R. M. Asimova, and A. N. Perepelkie, SPE Transactions, 2, 227 (1962).

6. G. Pezzin, G. Ajrold, and C. Garbuglio, $J$. Appl. Polym. Sci., 11, 2553 (1967).

7. L. M. Robeson, Polym. Eng. \& Sci., 9, 277 (1969).
8. E. Jenckel and R. Heusch, Kolloid Z., 13089 (1953).

9. J. D. Ferry, "Viscoelastic Properties of Polymers," 2nd ed, Wiley, New York, N. Y., 1970, Chapter 11.

10. G. C. Cerry and T. G. Fox, Advan. Polym. Sci., 5, 261 (1968).

11. J. P. Mercier, J. J. Aklonis, M. Litt, and A. V. Tobolsky, J. Appl. Polym. Sci., 9447 (1965).

12. Y. Ishida and S. Matsuoka, Amer. Chem. Soc., Polymer Preprints, 6, No. 2, 795 (1965).

13. K. H. Hellwege, J. Hennig, and W. Knappe, Kolloid-Z., 186, 29 (1962).

14. G. W. Miller, "Thermal Analysis," Volume 1, Academic Press Inc., London, 1969.

15. S. Matsuoka and Y. Ishida, J. Polym. Sci., 14 247 (1966).

16. A. J. Kovacs, Advan. Polym. Sci., 3, 486 (1963).

17. L. J. Garfield and S. E. Petrie, J. Phys. Chem., 68, 1750 (1964).

18. M. G. Wyzgoski, to be published. 